\title{
Dois países, três Estados: a experiência dos palestinos nas fronteiras do sul do Brasil.
}

\author{
Two countries, three States: the palestinians' experience at Brazil's \\ southern borders.
}

\author{
Dra. Letícia Núñez Almeida ${ }^{1}$; Jennifer da Silva Pereira²; Nathan Bueno Macêdo ${ }^{3}$; Agnes \\ Félix Gonçalves ${ }^{4}$; Rafael Augusto Masson Rocha ${ }^{5}$.
}

\author{
${ }^{1}$ Inalmeida@usp.br, Universidade Federal do Pampa, ${ }^{2}$ agnesfgoncalves@gmail.com, \\ Universidade Federal do Pampa; ${ }^{3}$ jen.jps@ hotmail.com, Universidade Federal do Pampa; \\ ${ }^{4}$ agnesfgoncalves@gmail.com, Universidade Federal do Pampa; ${ }^{5}$ rmassonrocha@ gmail.com, \\ Universidade Federal do Pampa.
}

\begin{abstract}
Resumo
As fronteiras brasileiras vêm sendo observadas com mais atenção por pesquisadores das ciências sociais e, especialmente, pelas políticas de segurança pública brasileiras. Esse interesse é recente e inédito, ainda sabe-se pouco sobre os cerca de dezessete mil quilômetros que separam e aproximam o Brasil dos seus países vizinhos. Entretanto, muitos conceitos vêm sendo discutidos no intuito de tornar a temática das fronteiras menos "romântica" e mais acadêmica, ao menos em tese. Como por exemplo o de Cidades-gêmeas, de Zona de Fronteira etc. Nesse contexto, a região sul do país, a que faz fronteira com a República Oriental do Uruguai e com a Argentina, torna-se um espaço frutífero para análises empíricas, tendo em vista que é a que possui mais municípios conurbados, cento e noventa e sete só no estado do Rio Grande do Sul. Dessa forma, o presente estudo visa compreender um pouco das dinâmicas urbanas dessas cidades-gêmeas, analisando alguns processos de socialização como é o caso dos Palestinos, especialmente na fronteira de Sant'Ana do Livramento (BR) e Rivera (ROU), utilizando-se dos conceitos de Pórtico e de Cidade para pensar esses espaços que não são nem brasileiros nem uruguaios.
\end{abstract}

Palavras-Chave: BRASIL, CIDADES GÊMEAS, FRONTEIRAS, PALESTINOS, URUGUAI.

\begin{abstract}
Brazilian borders have been being observed more closely by social science researchers and especially by Brazil's public security policies. This interest is recent and unprecedented, yet little is known about the approximately seventeen thousand kilometers that both separates and approaches Brazil of its neighboring countries. However, many concepts are being discussed in order to make the issue of borders less "romantic" and more academic, at least in theory. Such as the Twin-Cities, Border Zone etc. In this context, the South region, which borders the Eastern Republic of Uruguay and Argentina, it is a fruitful area for empirical analysis, considering that is the one that has the greater number of adjacent municipalities, one hundred and ninety seven conurbations only in the state of Rio Grande do Sul.Thus, this study aims to understand part of the urban dynamics of these twin-cities, analyzing some socialization processes as in the case of the Palestinians, especially in the border between Sant'Ana do Livramento (BR) and Rivera (ROU), using the concepts of Portico and City to think these spaces that are neither brazilians nor uruguayans.
\end{abstract}




\section{INTRODUÇÃO}

... el concepto de frontera no debe ser entendido como limite o muro que separa, sino como elespacio continuo de alteridade, donde se encuentranlos universos simbólicos diferentes y desiguales, loscualesdeben ser explorados y estudiados, para luego ser franqueados e interados. (CARRIÓN; ESPÍN, 2011, p.13)

As Fronteiras são limites terrestres que podem ser naturais quando rios, oceanos, etc. surgem como evidências físicas de seu traçado; e artificiais quando representadas por linhas geodésicas. É a delimitação espacial do Estado. Mais do que linhas divisórias, são pontos de contato com outros países e suas realidades sociais, econômicas e políticas. Nesse sentido, os conceitos de limite e fronteira são facilmente tomados como sinônimos, porém esses termos apresentam importantes diferenças que devem ser explicitadas. A fronteira se caracteriza por ser um lugar de comunicação e troca entre dois domínios territoriais distintos (RIBEIRO, 2001). Ela é uma construção social materializada nas relações entre os povos que vivem o cotidiano do contato e das trocas. A fronteira é do "domínio dos povos", enquanto que o limite pertence ao "domínio da alta diplomacia" (MACHADO, 2000). Isso significa que se a fronteira surge como uma realidade espacial e social, com características próprias de lugares de contato, o limite está ligado a uma abstração política, um separador, uma criação feita através de acordos diplomáticos, no intuito de delimitar soberanias e jurisdições, neste caso, os limites do Estado-Nação.

Para Magnoli (1986), a complexidade social das regiões de fronteira assusta os Estados; segundo o geógrafo, os motivos do susto podem ser apontados na definição clássica do geógrafo francês Jaques Ancel:

Fronteira é uma isóbara política que fixa o equilíbrio entre duas pressões. Isóbara, em mapas e cartas, é a linha que separa áreas de pressão atmosférica diferente; ao longo de seu traçado, a pressão é constante. (ANCEL apud MAGNOLI, 1986, p.10).

Espaços de pressão, tensões e disputas, terras de ninguém e territórios sem lei são algumas das formas como as fronteiras são qualificadas. Mas de quais pressões e tensões está se falando? Pouco se sabe sobre as fronteiras brasileiras para além dos circuitos criminosos de tráfico e contrabando, estes que acabam por caracterizá-las como um risco para a defesa do território nacional.

Este trabalho, de caráter descritivo e exploratório, faz parte de uma pesquisa de Tese de Doutorado que está em andamento. Nesse sentido, o objetivo deste estudo é iniciar uma análise das dinâmicas urbanas e sociais na Fronteira do Brasil com a República Oriental do 
Uruguai (doravante Uruguai), buscando compreender como se dá a socialização nesses espaços que são de separação, de encontro e também de formação de culturas.

\section{AS CIDADES-GÊMEAS NA FRONTEIRA DO BRASIL COM O URUGUAI}

O Brasil possui aproximadamente dezessete mil km de fronteiras. Com a extensão de cerca de 8,5 milhões de $\mathrm{km}^{2}$, faz divisa com dez países da América do Sul, exceto com o Chile e o Equador. Desde o século XIX, o Brasil tem mantido uma faixa de fronteira, ou seja, uma área a partir da divisa do país com seus vizinhos que é regida por normas especiais. A faixa compreende a extensão de cento e cinquenta quilômetros de largura, ao longo da fronteira terrestre, e sua regulação legal ${ }^{1}$ está ligada à defesa nacional e, portanto, de cerceamento de diversas atividades econômicas nessa faixa a estrangeiros. (ALVAREZ et al, 2011)

A linha que delimita a fronteira brasileira pode ou não estar situada nos centros urbanos dessa faixa de $150 \mathrm{~km}$. Diferente das fronteiras chamadas de cidades-gêmeas, ou "fronteiras vivas", onde a linha de fronteira separa (ou une) de forma central cidades de países distintos. Dos 710 municípios na faixa de fronteira do Brasil, 197 fazem parte do estado do Rio Grande Sul, sendo dezenove (19) situados na linha de fronteira e dez (10) cidadesgêmeas, fazendo fronteiras terrestres e fluviais com cidades do Uruguai e da República da Argentina, como pode ser visualizado no mapa abaixo:

\footnotetext{
${ }^{1}$ A faixa de fronteira é mencionada na Constituição Federal, de 1988, no seu art. 20 , § $2^{\circ}$, e uma regulação específica das atividades permitidas e proibidas está contida na lei no 6.634, de 1979.
} 


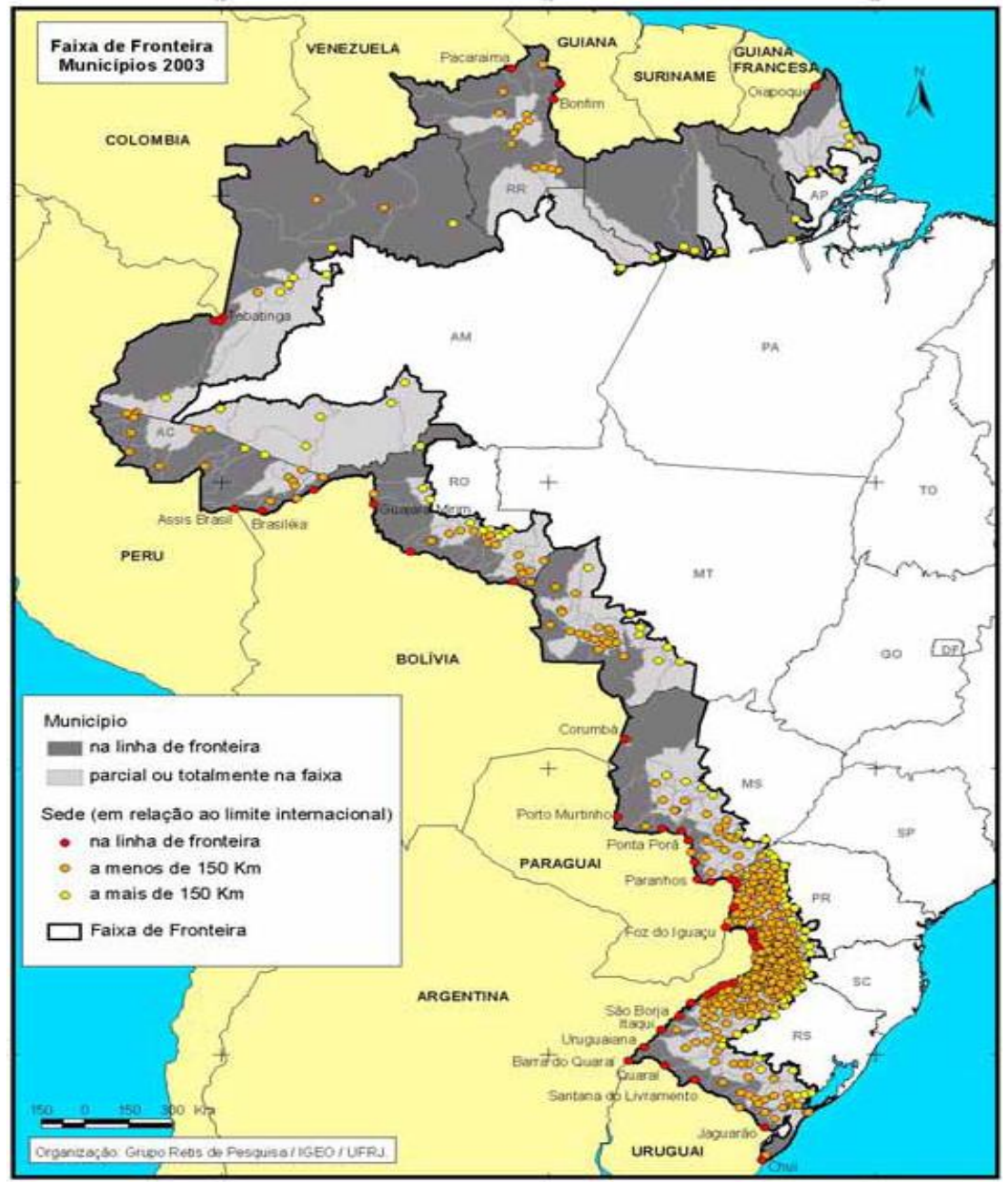

Figura 1 - Mapa da faixa da fronteira brasileira

Fonte: SILVA (2011).

Assim, a fronteira sulina é a que possui o maior número de "fronteiras vivas" na faixa brasileira e é o recorte empírico deste estudo. Pretende-se, a partir da experiência local, compreender melhor do que se está falando quando o tema é fronteiras, enquanto únicas, cada qual com a sua dinâmica urbana.

\subsection{A FRONTEIRA DA PAZ}

La frontera entre el estado brasileño de Rio Grande do Sul y la República Oriental delUruguay representa uno de losescenarios de convivencia luso-hispanico más intenso y prolongado. Los limites territoriales entre estos dos países están formados por muchasciudadesgemelas que, constituyen virtualmente, em cada caso, uma sola ciudad com vida econômica y cultural entremezeada, como es el caso de ArtigasQuaraí, Rivera-Livramento, Aceguá- Acegua, Rio branco-Jaguarão, Chui-Chuí. (AMARAL apud SILVA, 2009, p.81-82) 
A fronteira entre o Brasil e o Uruguai compreende os Departamentos situados ao norte do território uruguaio e a metade sul do estado brasileiro do Rio Grande do Sul. São cinco os municípios na linha de fronteira com as ciudades do Uruguai: 1) Santana do Livramento Rivera; 2) Chuí - Chuy; 3) Jaguarão - Río Branco; 4) Aceguá - Acegua; 5) Quaraí - Artigas; 6) e Barra do Quaraí - Bella Unión. No RS, também se encontram cidades fronteiriças com a Argentina, que podem ser do tipo fluvial e/ou terrestre.

A metade sul do Rio Grande do Sul é região que apresenta os piores indicadores sociais e econômicos do estado, da mesma forma, é a região indicada como uma das que possui a maior diversidade de eventos criminosos do Brasil. Sendo entendida, tanto pela academia quanto pelo governo federal, como uma zona onde a violência está institucionalizada em uma cultura da violência, que sempre predominou na resolução de conflitos. Nesse contexto, a fronteira viva das cidades de Sant'ana do Livramento (Brasil) e Rivera (Uruguai), como exposto na imagem abaixo, também conhecida como a Fronteira da Paz, possui em torno de 160 mil habitantes; é o principal núcleo urbano encravado em pouco mais de mil quilômetros de fronteira entre Brasil e Uruguai. Recebe esse nome por ter uma história de relações pacíficas entre os dois países, foi declarada legalmente ${ }^{2}$ pelo Presidente Lula como a cidade-símbolo da integração brasileira com os países membros do MERCOSUL. (ALMEIDA, 2011)

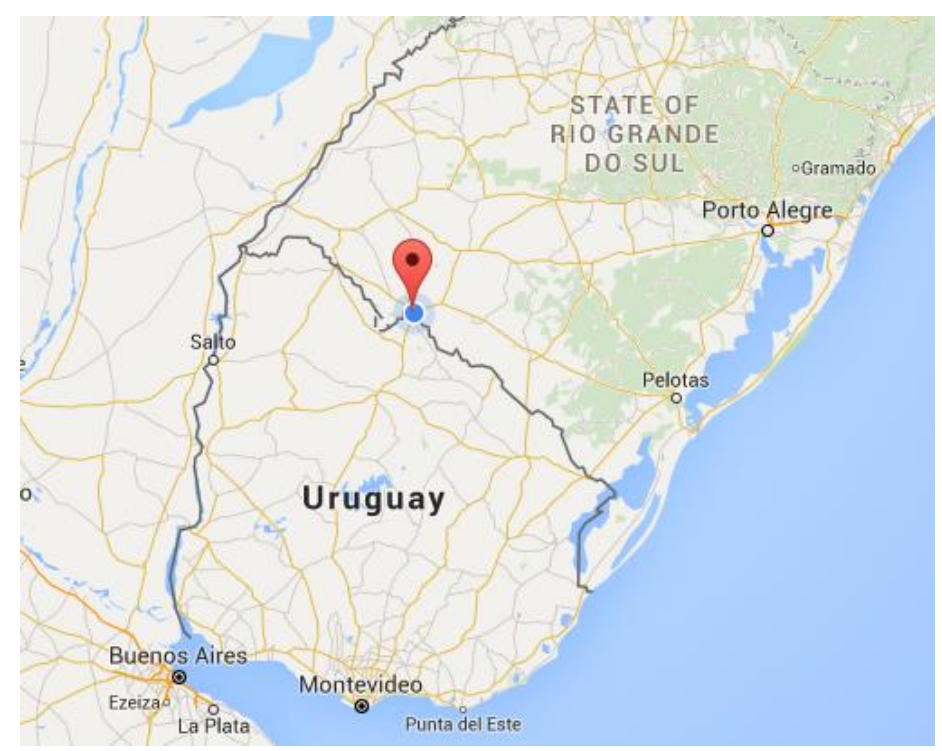

Figura 2 - Fronteira da Paz marcada no mapa do Rio Grande do Sul e do Uruguai.

Fonte: GOOGLE MAPS (2015).

2 BRASIL. Lei $\mathrm{N}^{\mathrm{o}}$ 12.095/2009. Disponível em: www.planalto.gov.br/ccivil_03/_ato2007-2010/2009/lei /112095.htm. Acesso em: 20 jul. 2012. 
A Fronteira da Paz registra mais de 100 quilômetros de faixa de fronteira seca com o Uruguai. Na área urbana foi construída a Praça ou Parque Internacional, no entorno da linha divisória, a única praça binacional do mundo, que foi inaugurada em 1943 e é palco de experiências curiosas como a narrada por Ruiz (1996), no seu estudo comparativo entre a Fronteira da Paz e a de Tijuana com San Diego:

\begin{abstract}
Al llegar a Livramento - La manera en que lo llaman los brasileños_, decidi salir inmediatamente hacia la línea internacional;(...) Sin embargo, no veí ani aduana ni agentes de migración, ni cerca, enfin, nada que yo asociaba con una frontera internacional. Atenta a cualquier signo que marcara el comienzo de una frontera, entré al parque y a lamitad le pregunté a un comerciante ambulante, primero em portugués y luego em español al escuchar su acento, donde estaba Uruguay. En una mezcla de los dos idiomas me contestó "vai para allá". Seguí adelante hasta llegar a una calle central donde entré a una tienda y le pregunté a la dependienta donde empezaba Uruguay. "Está usted em Uruguay", me contestó. (RUIZ, 1996, p.6).
\end{abstract}

Segundo Dorfman (2006) e Assef (2009), a fronteira em questão é apresentada como única, em comparação com outras fronteiras internacionais. Entre as razões para tal excepcionalidade listam-se: os vínculos transfronteiriços intensos e cotidianos; o compartilhamento do centro urbano; a livre circulação, sem a necessidade de apresentação de documentos; a ausência de ascendência de uma cidade sobre a outra (como é o caso na fronteira México-EUA); o entrelaçamento da infraestrutura (estradas, aeroporto, esgotos, saúde, educação, controle de fronteiras), etc. (ALMEIDA, 2011). A seguir, fotos do Parque Internacional, que representam a Fronteira da Paz:

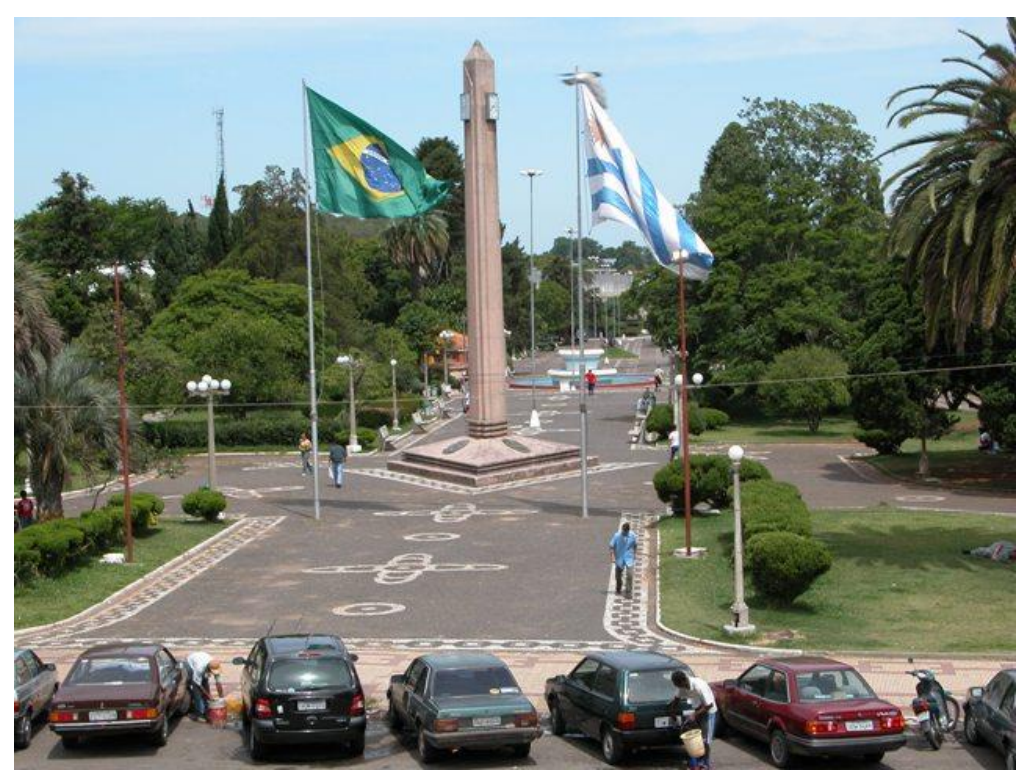

Figura 3 - Foto do Parque Internacional de Livramento e Rivera.

Fonte: CLICRBS (2010). 


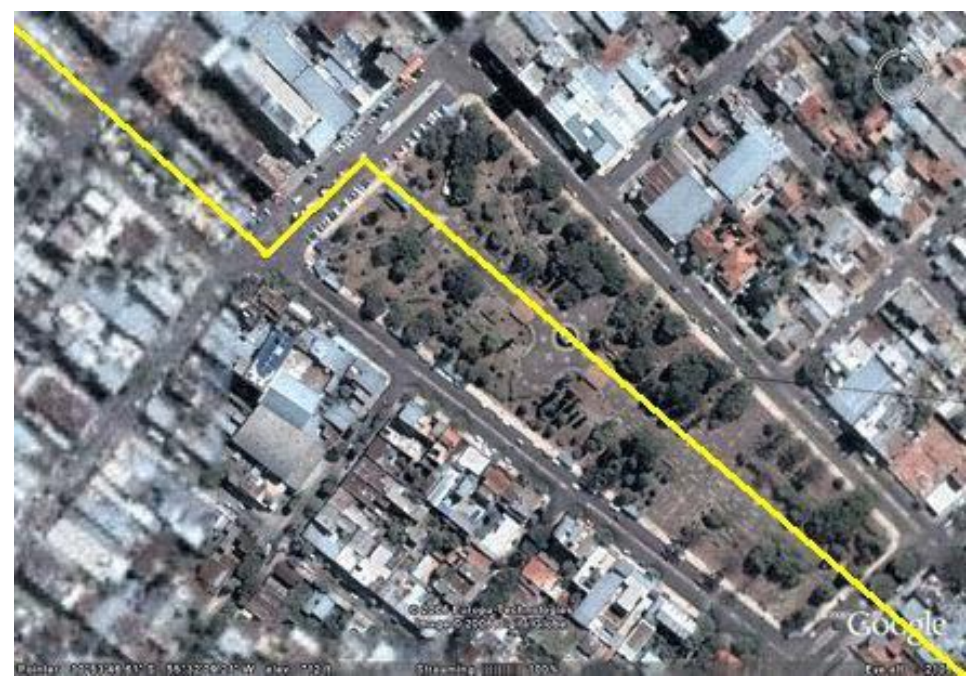

Figura 4 - Visão de satélite do Parque Internacional, com a linha de fronteira em amarelo. Metade inferior esquerda, Rivera; metade superior direita, Santana do Livramento.

Fonte: CASSANEGO et al. (2012, p. 199).

Essa integração não diminui as desigualdades econômicas locais que refletem a situação nacional de cada país, essa é a razão que faz com que os fronteiriços vivam na e da fronteira, se utilizando das vantagens em relação ao mercado de trabalho, serviços e oscilações cambiais ora de um país e ora de outro. Brasileiros consultam com médicos uruguaios, estudam, trabalham, moram, casam em Rivera, da mesma forma que uruguaios são hospitalizados no Brasil, compram seus mantimentos, casas e carros em Livramento. É habitual que pessoas que vivam em um lado da linha divisória e trabalhem no outro lado; como também é possível comprar com dólares americanos e pesos uruguaios no comércio brasileiro e vice-versa. O idioma próprio da fronteira é o portuñol, compartilhado por grande parte da população, da mesma forma que não raro os fronteiriços votam nos dois países por serem dobles chapa, ou seja, possuem dupla nacionalidade, são santanenses e riverenses ${ }^{3}$, o termo faz referência aos carros, motos e charretes que circulavam pela Fronteira com duas placas, uma brasileira e a outra uruguaia. (ALMEIDA, 2011)

Para os fronteiriços a separação/união entre os dois países está delimitada claramente, trata-se da linha divisória, invisível para um não-local e evidente para quem mora nesses municípios. A "linha", como é denominada habitualmente, aparentemente inexistente aos visitantes, é frequentada por camelôs, cambistas e contrabandistas. Se vierem policiais de uma nacionalidade, é só passar de um lado para o outro, fora da alçada da autoridade. É mais um

\footnotetext{
${ }^{3}$ Respectivamente os que nascem em Sant'Ana do Livramento e os que nascem em Rivera. 
espaço aberto do que uma linha de demarcação geopolítica de limites, mas ele existe e se coloca presente o tempo todo nas relações.

\subsection{A FRONTEIRA ENTRE O "DE FORA"(OU DE LONGE) E O "DE DENTRO"(OU DE PERTO) - ESCRITO NA TERCEIRA PESSOA}

Este trabalho é um exercício de análise da Fronteira, como um espaço onde formas de socialização são vivenciadas a partir das características político-geográficas das cidadesgêmeas de Sant'Ana do Livramento e Rivera. A reflexão proposta se dá sob o desafio constante de desenhar e compreender esse objeto de estudo, através de um olhar "de fora" e "de dentro" no sentido proposto por Geertz (2001, p.88). Explicamos: uma das autoras nasceu na Fronteira, é doble-chapa, filha de mãe uruguaia e pai brasileiro, neta de contrabandistas de couro uruguaios e de tropeiros de gado brasileiros. Alfabetizada em um colégio brasileiro, mas tinha aulas de inglês em uma escola uruguaia, com material escolar uruguaio, caderno com foto do Artigas ${ }^{4}$, o primeiro livro que li foi em espanhol. Os outros três autores são brasileiros de diferentes estados brasileiros, Santa Catarina, São Paulo e Rio de Janeiro, todos moram na Fronteira e vivem a possibilidade, naturalmente, consumir a cultura de ambos os países, como, por exemplo, as comidas, músicas e costumes.

O cotidiano de quem mora na parte central do município de Livramento está rodeado que estereótipos fronteiriços, como os cambistas, os ônibus com cartazes em espanhol e em português, as oscilações cambiais, os atendentes de lojas falando os dois idiomas e ainda o árabe, escutando o alcorão etc.

Faço esse breve relato na tentativa de aclarar do que estamos falando quando dizemos que sou nativa, para, a partir daí, buscar caminhos para sintonizar esse olhar doble-chapa, apropriado dos sistemas simbólicos (GEERTZ, 2001, p.107), com o da pesquisa acadêmica e os seus conceitos de experiências-distantes. O exercício de estar inevitavelmente envolvidos por experiências afetivas, muitas delas inconscientes, e ter isso presente tanto para aproximarse, quanto para distanciar-se do campo, não é tarefa simples.

Geertz (2001) trabalha essa questão a partir dos conceitos de "experiência-próxima" e da "experiência-distante" . A primeira é fruto da vivência do interlocutor e por isso é transmitida de forma natural, com familiaridade sobre o que se está falando, enquanto a segunda se refere a uma construção utilizada pelo pesquisador para atingir seus objetivos científicos. Nas palavras do autor:

\footnotetext{
${ }^{4}$ General José Gervasio Artigas, político, militar e herói uruguaio.

${ }^{5}$ Categorias formuladas pelo psicanalista Heinz Kohut. (GEERTZ, 2001, p.87)
} 


\begin{abstract}
A verdadeira questão - a que Malinowski levantou ao demonstrar que, no caso de "nativos", não é necessário ser um deles para conhecer um relaciona-se com os papéis que os dois tipos de conceitos desempenham na análise antropológica. Ou, mais exatamente, como devem estes ser empregados, em cada caso, para produzir o modus vivendi de um povo que não fique limitada pelos horizontes mentais daquele povo - uma etnografia sobre bruxaria escrita por uma bruxa - nem que fique sistematicamente surda às tonalidades de sua existência - uma etnografia sobre bruxaria escrita por um geômetra. (GEERTZ, 2001, p.88).
\end{abstract}

Utilizando o exemplo do autor, no caso da bruxa, de que estratégias pode se armar o pesquisador, que também é nativo, para que as experiências próximas e distantes possam dialogar ao realizar pesquisa?

Acreditamos que estar atentos para não perder de vista o olhar distanciado (MAGNANI, 2002) seja um instrumento fundamental nesse processo de desenho do objeto de investigação, reconhecendo os arranjos nativos e buscando trabalhá-los em um plano mais geral.

Ao mesmo tempo em que somos "de dentro", a distância geográfica e a formação pessoal e acadêmica criam um outro lugar, também "somos e estamos de fora". Se por um lado, no nosso imaginário, os municípios de Livramento e Rivera são uma cidade só, que se chama Fronteira da Paz e que é sempre compreendida a partir de integração afetuosa e mistura democrática de culturas; por outro, visualizamos um romantismo e uma opção por não olhar esse espaço como Cidade e seus moradores nas suas diversas formas de sociabilidade. Uma hipótese é que um olhar acadêmico de fora e de longe (MAGNANI, 2002) busca sempre o mesmo objeto nessa região de fronteira, que é a mesma razão que faz os turistas irem até lá fazer compras: culturas misturadas, fácil acesso a produtos uruguaios e importados, ou seja, contrabando e descaminho em pequena escala, etc. É uma visão institucional do Estado e da mídia sobre a região fronteiriça brasileira. Da mesma forma, quando o olhar é de perto e de dentro (MAGNANI, 2002), mesmo em pesquisas acadêmicas, a história nostálgica entre mocinhos e bandidos tende a se repetir, é a Fronteira da Paz entendida como uma totalidade $a$ priori, uma comunidade em que os membros se conhecem e estão ligados por padrões de troca interpessoais harmônicas.

É o que Georg Simmel (2005) descreve como cidade pequena em seu trabalho As grandes cidades e a vida do espírito (1903); fechada em si mesma, onde os habitantes estão baseados no ânimo entre as pessoas, nas suas individualidades e nas relações pautadas pelo sentimento. Assim tem sido analisada a fronteira, como um território onde os indivíduos agem de acordo com suas emoções e de forma a limitar a expansão da racionalidade e do 
individualismo, ou como categoriza o autor: “... na qual se conhece quase toda pessoa que se encontra e se tem uma reação positiva com todos."(SIMMEL, 2005, p. 582).

A ideia deste trabalho é olhar para a fronteira por um olhar inverso, como a cidade grande de Simmel (2005), onde as relações e oportunidades dos habitantes costumam ser variadas, complicadas e mediante a acumulação de homens com interesses diferenciados. Nas palavras do autor:

Com isso as cidades grandes obtêm um lugar absolutamente único, prenhe de significações ilimitadas, no desenvolvimento da existência anímica; elas se mostram como uma daquelas grandes formações históricas em que as correntes opostas que circunscrevem a vida se juntam e se desdobram com os mesmos direitos. (SIMMEL, 2005, p. 589)

Mesmo sendo um aglomerado pequeno, nossa hipótese é a de que há várias centralidades (FRÚGOLI apud MAGNANI, 2002) nessa Fronteira, com dinâmicas e alteridades que nelas e delas decorrem. Dessa forma, pretende-se, neste trabalho, iniciar uma análise dessas cidades-gêmeas utilizando como referencial teórico os conceitos de Pórtico (MAGNANI, 2002) e de Cidade (WEBER, 2009).

\title{
3 A FRONTEIRA: TERRITÓRIO DE MUITAS LEIS
}

\begin{abstract}
Unidas por uma rua, que também é a fronteira que separa o Brasil do Uruguai, Livramento e Rivera vivem juntas, como duas irmãs numa mesma casa: dividindo diversões, tarefas, brincando e brigando - ao sabor das guerras, dos parentescos, do futebol, do câmbio. (...) Por mais amáveis e graciosos que possam ser, gêmeos são sempre estranhos. E essas duas cidades em uma (que parece uma terra dividida em dois) não deixam de ter suas complicações: cidade(s) em que você se distrai e faz um contrabando. Cidade(s) em que os automóveis têm duas placas. Cidade(s) em que é conveniente olhar para os anúncios publicitários para os anúncios publicitários para saber se já é Uruguai ou ainda é Brasil. (BOJUNGA apud ALMEIDA, 2011):
\end{abstract}

As fronteiras sulinas, como as demais regiões do Brasil, possuem características culturais e dinâmicas cotidianas diversas, mesmo estando localizadas na região da Pampa gaúcha ${ }^{6}$, onde, desde sempre, as atividades econômicas giram em torno da agropecuária e do contrabando de mercadorias e gado (ALBORNOZ, 2000). Nesse sentido, as cidades-gêmeas são espaços onde aparentemente há muitas misturas culturais, como é o caso do uso do portuñol, do casamento entre pessoas de nacionalidades distintas e outras já mencionadas. Num primeiro momento, isso causa a sensação de que os moradores dessa região não se identificam claramente com nenhum dos dois países fronteiriços, entretanto a noção de

\footnotetext{
${ }^{6}$ Região de planícies e coxilhas formada por parte do Rio Grande do Sul, Argentina e Uruguai.
} 
nacionalidade é mais complexa do que se apresenta inicialmente. Para Albuquerque (2010), há uma relação ambígua entre língua e nacionalidade nas zonas de fronteira; os governantes e educadores locais, no caso da fronteira do Brasil com o Paraguai, acreditam que os países estão perdendo suas identidades nacionais em algumas fronteiras, pois os moradores são contaminados pela língua e pela música do país vizinho. Essa pode ser uma visão contaminada pela ideia difundida no senso comum, mídia e políticas públicas brasileiras do que é a fronteira e do estereótipo pré-concebido das pessoas que vivem lá. Talvez, ainda, os próprios fronteiriços comprem, consciente e inconscientemente, o discurso de que eles próprios não fazem parte do país, que vivem em uma terra de ninguém, sem Estado e sem lei.

No caso de Livramento e Rivera, em muitas ocasiões não se sabe se está no lado oriental $^{7}$ ou no brasileiro, tendo em vista que são mais de 100 quilômetros de faixa de fronteira seca entre as duas cidades. Entretanto, há um centro comercial, ao longo da linha divisória, um comércio de barracas de camelôs, lanchonetes, cambistas, bicheiros, quinieleros $^{8}$ etc., e é por onde passam centenas de turistas para fazer compras nos Free shops do lado uruguaio. Como retratam as imagens 05 e 06, abaixo:

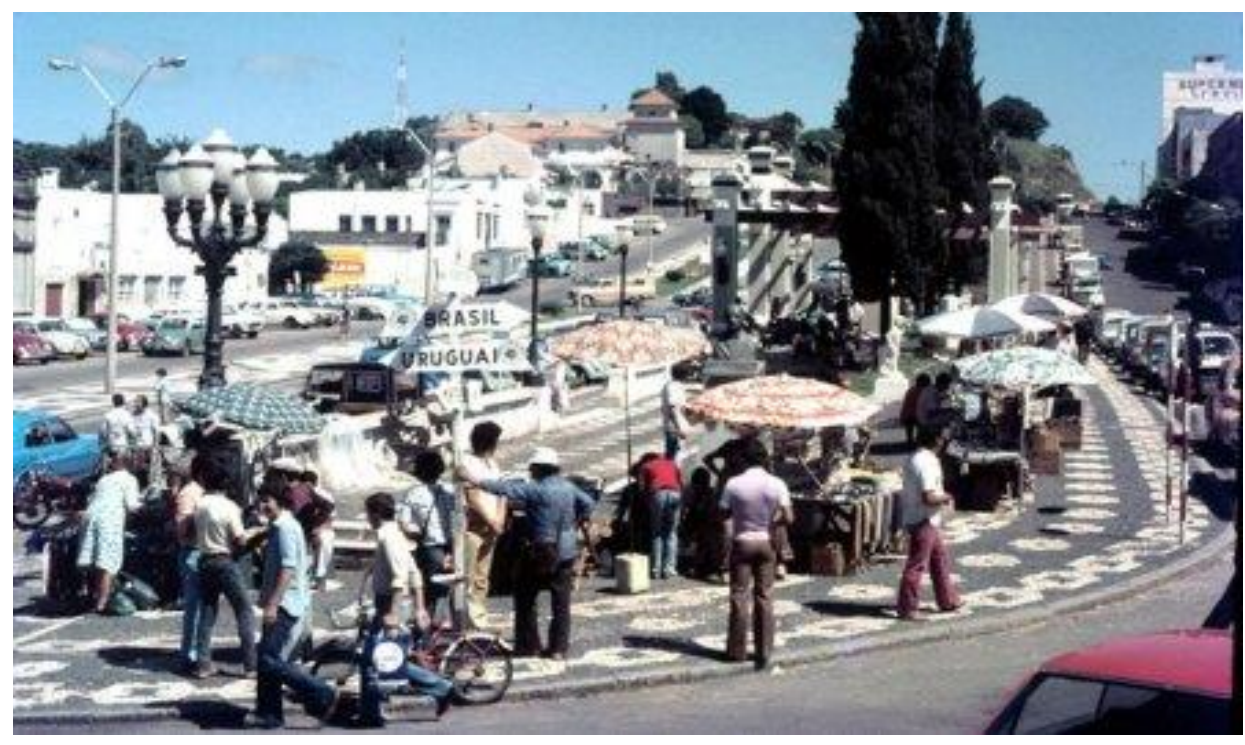

Figura 05 - Praça Flores da Cunha, 1980, com seus cambistas e camelôs.

Fonte: CANABARRO (2009).

\footnotetext{
${ }^{7}$ Termo regional para designar o Uruguai.

${ }^{8}$ Que fazem as apostas da Quiniela, jogo do bicho uruguaio.
} 


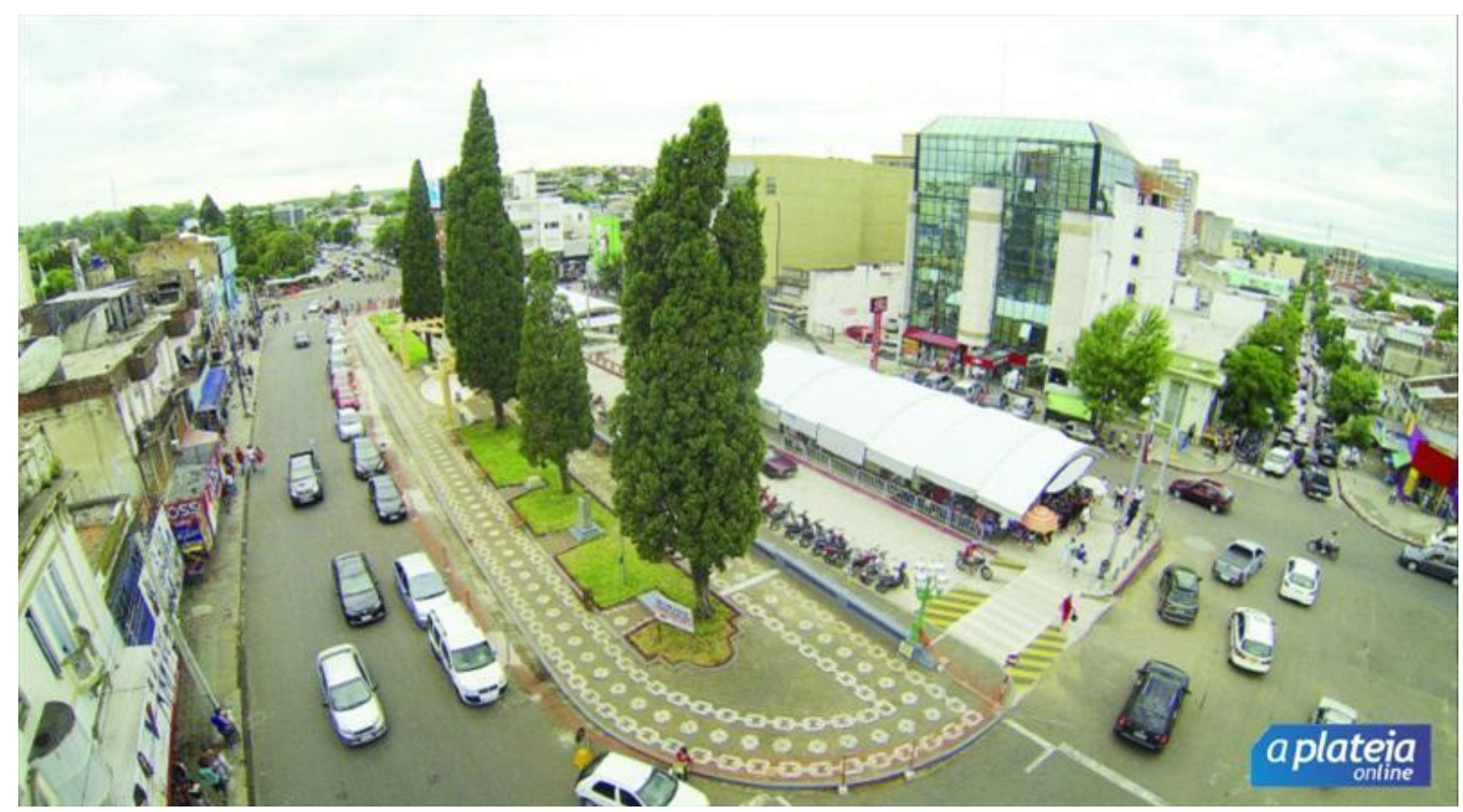

Figura 4 - À esquerda da avenida está Livramento e à direita Rivera. No final da foto, à esquerda, está a Praça Flores da

Cunha com seus camelôs.

Fonte: BACHIO (2014, p. 1).

Esse espaço que culturalmente não é nem brasileiro nem uruguaio, possui um ethos próprio construído a partir do encontro entre os Estados. No âmbito local, a separação e a defesa de território não fazem sentido, tendo em vista que as pessoas vivem na e da fronteira, isso se dá especialmente nas cidades-gêmeas, onde as economias assimétricas sustentam as duas cidades de forma integrada. Esse fenômeno é fruto das oscilações cambiais e das legislações de cada país, o que é ilegal de um lado da fronteira pode não ser do outro, um produto ou serviço pode ter o preço mais alto no Brasil por causa dos impostos, valendo a pena comprar no Uruguai, sendo que, nas cidades-gêmeas, isso significa atravessar a rua. Grande parte do êxito das atividades ilegais deriva precisamente do saber explorar o potencial dessa integração face à fragilidade da economia legal. Como explica Dorfman (2006), em sua tese sobre o contrabando nessa fronteira:

O comércio local beneficia-se da condição fronteiriça. Em Livramento, os supermercados e casas de material de construção, em determinadas conjunturas, vendem quase exclusivamente para clientes uruguaios (do norte do país e da capital). Os tipos de produtos pouco se alteram, oscilando o volume com a variação cambial: confecções, gêneros alimentícios, madeira, derivados de petróleo e material de construção são comprados no Brasil; laticínios, farináceos, carnes, lãs, tecidos finos, cristais e produtos de luxo são adquiridos no Uruguai. É comum a presença de estabelecimentos comerciais localizados em ambas as cidades e pertencentes a um mesmo dono, que busca fazer frente às oscilações cambiais. $\mathrm{O}$ centro comercial localiza-se ao longo da linha de fronteira, explicitando seu direcionamento ao exterior de cada uma das duas cidades. (DORFMAN, 2006, p. 03) 
O centro localizado na linha divisória não é o único desse local. Do lado brasileiro, o centro comercial se dá na Rua dos Andradas, no trecho que vai do Parque Internacional até a Praça General Osório, onde estão situadas a sede da Prefeitura Municipal, a Igreja Matriz, a Casa de Cultura e as agências dos principais bancos brasileiros. Nesse caminho, o idioma que chama a atenção não é o portuñol, mas sim o árabe, língua falada pelos libaneses e palestinos, proprietários de grande parte do comércio santanense, formando outras fronteiras.

Parte dos santanenses não possui nenhum tipo de relação comercial com Rivera, não falam ou entendem o espanhol, desconhecem a cultura, a história e a política uruguaia, se orgulham de dizer que não gostam dos $\operatorname{castilhanos}^{9} \mathrm{e}$ não atravessam a linha nem para fazer compras. Só chegam até o comércio do centro da linha, que poderia ser caracterizado como pórtico, no sentido de ser um espaço que não pertence nem a um país, nem ao outro (MAGNANI, 2002).

Nesse sentido, o mesmo ocorre no município uruguaio, o centro comercial está na Av. Sarandi, no trecho que vai do Parque Internacional até a sede da Polícia Aduaneira, no final da avenida. Aí estão os free shops lotados de turistas fazendo compras, as lojas de roupas de lã e couro uruguaios, a Plaza Artigas rodeada pela Iglesia Matriz, a sede da Intendencia ${ }^{10}$, o Banco de la Republica e a Delegacia de Polícia. Não há árabes. Desse lado também não há só empatia e integração, muitos riverenses não falam português, só conhecem a cultura brasileira através das novelas globais e se orgulham de dizer que não gostam dos $\operatorname{macacos}^{11}$. Quando visitam o Brasil o fazem como turistas, consomem produtos, mas seus filhos não estudam em escolas brasileiras.

Em relação à peculiaridade dessas cidades-gêmeas, afirma Copstein (apud DORFMAN, 2006), que Santana do Livramento e Rivera são uma única cidade, sujeita a duas soberanias. O que pode ser interpretado de outra forma, ou seja, essa cidade única, como afirma a autora, possui a sua soberania, com suas leis e limites próprios, "terra de muitas leis", diferente dos ordenamentos fixados para o território brasileiro e o uruguaio. São cidades dentro desse perímetro urbano, cada qual com o seu centro e sua identidade. Nesse sentido, Albuquerque (2010), na sua pesquisa sobre migrantes brasileiros que vivem no Paraguai, os brasiguaios, investigou a "identidade fronteiriça" na fronteira do Brasil com o Paraguai e as disputas políticas locais. Nesse sentido, o estudo mostra que as culturas que aparentemente se

\footnotetext{
${ }^{9}$ Termo utilizado pelos brasileiros para chamar os uruguaios.

${ }^{10}$ Prefeitura Municipal.

${ }^{11}$ Termo utilizado pelos uruguaios para chamar os brasileiros.
} 
misturam, a partir de um olhar de fora, guardam uma complexidade de movimentos que delimitam cada nacionalidade em contraste com a de seus países vizinhos. Explica o autor:

\begin{abstract}
Quando saía de uma cidade pertencente a um país e ingressava em um município vizinho, mas já de uma outra nação, tinha a sensação de uma maior distância geográfica propiciada pela distinção cultural. As diferenças culturais e políticas produzem uma sensação de distanciamento geográfico entre cidades vizinhas, como nos casos de Cidade do Leste (PY) e Foz do Iguaçu (BR), Posadas (Ar) e Encarnación (PY) e Pedro Juan Caballero (PY) e Ponta Porã (BR). (ALBUQUERQUE, 2010, p.23)
\end{abstract}

É evidente que esse encontro de culturas forma novas dinâmicas econômicas e sociais que estão em movimento e não ficam paralisadas na fronteira como território. Entretanto, o que fica claro é que os outros centros comerciais e culturais não se dissolvem em razão dessa mistura; o desafio é explorar essa complexidade de limites partindo da ideia de que, sim, a fronteira é um espaço de integração e circulação democrática e aberta (em muitos lugares isso não é verdade), ao mesmo tempo sua configuração geográfica cria redes, acentua diferenças e gera conflitos.

Didier Bigo, por exemplo, defende que as fronteiras devem ser analisadas de como redes complexas de trocas e de mobilidade e, ao mesmo tempo, de novas técnicas de controle e de identificação (BIGO apud ALVAREZ et al., 2011). Ou seja, é preciso pensar a fronteira como instituição, com sua dinâmica e especificidade, e não apenas como limites da centralização estatal.

Retomando a ideia de Pórtico, acredita-se que o centro dessa fronteira produz regras que ainda são pouco conhecidas, talvez por ser um lugar intermediário entre duas realidades bem definidas. Nas palavras de Magnani (2002):

Trata-se de espaços, marcos e vazios na paisagem urbana que configuram passagens. Lugares que já não pertencem à mancha de cá, mas ainda não se situam na de lá; escapam aos sistemas de classificação de uma e outra e, como tal, apresentam a “maldição dos vazios fronteiriços". Terra de ninguém, lugar de perigo, preferido por figuras liminares e para realização de rituais mágicos - muitas vezes lugares sombrios que é preciso cruzar rapidamente, sem olhar para os lados... (MAGNANI, 2002, p.23)

Insiste-se que a fronteira é apenas um local de passagem, no caso brasileiro, de passagem de mercadorias gerenciadas por organizações criminosas, de gado roubado e drogas. A questão que surge é o que realmente há nesse pórtico e quais as dinâmicas produzidas a partir dele. Esse é um dos desdobramentos que se pretende dar na continuidade desta pesquisa. Uma possibilidade teórica para pensar o Centro, ou a Linha, é que a partir desta se configura uma Cidade, no sentido proposto por Max Weber (2009), em sua Tipologia 
das cidades, tendo em vista que as relações comerciais estabelecidas nesse trecho da linha divisória estabelecem uma "localidade de mercado", nas palavras do clássico:

Somente queremos falar de "cidade" no sentido econômico, tratando-se de um lugar onde a população local satisfaz no mercado local uma parte economicamente essencial de suas necessidades cotidianas, e isto principalmente com produtos que a população local e dos arredores produziu ou adquiriu para a venda no mercado. (WEBER, 2009, p.409)

O centro econômico da fronteira cria um espaço de interlocução com outros mercados, tanto com o resto do território nacional dos dois países, quanto, e principalmente, com outras centralidades de Livramento e Rivera. Cada município possui sua localidade de mercado, muito distinta do espaço formado pelo encontro dos dois países, onde os moradores dos outros centros satisfazem as necessidades de consumo de suas economias em um mercado com "assentamento permanente" (WEBER, 2009, p. 410).

Sabe-se que centro entre é um encontro democrático de culturas, mas o que se pretende investigar a partir deste trabalho é o que está por trás desse pórtico, uma vez que não está vazio e possui características de Cidade, no sentido weberiano do termo. Para o global, que é o Estado, o local é a Fronteira como totalidade, mas ainda há um micro local, a linha, que com suas dinâmicas sociais, dá suporte a uma configuração geográfica e política que contempla a população de duas cidades.

Assim, acredita-se que o território não é unicamente um caminho de circulação de bens ou uma mistura de culturas que se dá de forma automática, as populações fronteiriças, o espaço físico e os habitantes produzem redes e processos que estão em movimento, não se estagnam no território das cidades-gêmeas.

\section{CONSIDERAÇÕES FINAIS}

A faixa da fronteira brasileira com os países da América Latina e Guiana Francesa ainda é pouco estudada pelas Ciências Sociais e tem sido objeto de investimento do Governo Federal, no sentido de pensar políticas públicas focadas na defesa dos limites do território nacional. Uma das principais preocupações desses projetos são as cidades-gêmeas, locais de livre circulação de pessoas e mercadorias entre diferentes países - porta de entrada de drogas, armas e outros produtos ilegais. O paradoxo é que mesmo que de forma ilegal, através do contrabando e do descaminho, há uma integração, produzida em uma ilegalidade que não é gerada só no local, mas também a partir de disputas de interesses políticos. 
Nesse trabalho, buscou-se dar início a uma análise a partir um enfoque voltado a compreender as dinâmicas sociais que se estabelecem nas cidades-gêmeas de Livramento e Rivera. Suas singularidades, para além de uma fronteira que usualmente é entendida ou como um espaço território facilitador da criminalidade, ou como um local onde há uma totalidade de integração e multiculturalismo, desenvolvido por meio de relações interpessoais de afeto entre hermanos.

Dessa forma, o objetivo deste breve estudo é pensar desenhos de possíveis questões a serem desenvolvidas no processo de pesquisa e de elaboração da Tese de Doutorado, cujo recorte empírico é as cidades-gêmeas da fronteira do Brasil com o Uruguai e a Argentina. A intenção foi propor alguns temas e questões para o início de uma análise, buscando novos caminhos teóricos, empíricos e metodológicos. Não há conclusões, apenas pistas e algumas ideias para os desdobramentos da pesquisa "mais geral", a partir das discussões apresentadas neste paper, a principal delas, que se acredita norteará os próximos passos, está relacionada à importância da multiplicidade de perspectivas quando o tema é fronteira.

Dessa forma, os pontos que foram levantados partem da ideia de que as misturas culturais não excluem as peculiaridades de cada país, ao contrário, podem reforçá-las no contato com o outro. Vista de fora, não há dúvidas de que a Fronteira da Paz possui o seu centro comercial, situado na linha divisória ao lado do Parque Internacional, entretanto propõe-se que há outras centralidades nos dois municípios ${ }^{12}$ que, mesmo independente da Linha, podem estar entrelaçadas por dinâmicas a serem investigadas.

Por um lado está a Fronteira binacional, com o seu centro que caracterizado aqui como Pórtico; de outro, as experiências de cada município e seus atores sociais. A questão é que todos fazem parte de um todo vivo, em movimento, e o desafio está em focar no local sem perder de vista suas inter-relações com o global, que aqui são as cidades-gêmeas.

Como explica Magnani:

(...) aqueles dois planos a que se fez alusão anteriormente - o da cidade em seu conjunto e o de cada prática cultural assignada a este ou àquele grupo de atores em particular - devem ser considerados como dois pólos de uma relação que circunscrevem, determinam e possibilitam a dinâmica que se está estudando. (MAGNANI, 2002, p.20)

Ainda em relação à importância de se ter presente as dinâmicas existentes entre o global e o local, acredita-se que a opção por um: “(...) bordejar dialético contínuo entre o

\footnotetext{
${ }^{12}$ Descrevemos brevemente duas delas, mas certamente há outras, situadas em bairros mais afastados e rurais, conhecidos como cercanias, como por exemplo: Palomas, Caverá, Cerro Chato, Empalme, Masoller, etc.
} 
menor detalhe nos locais menores, e a mais global das estruturas globais, de tal modo que ambos possam ser observados simultaneamente, proposto por Geertz (2001, p.105), pode ser interessante como complemento ao caminho proposto acima por Magnani. Nas palavras de Geertz:

\footnotetext{
Saltando continuamente de uma visão da totalidade através das várias partes que a compõem, para uma visão das partes através da totalidade que é casa de sua existência, e vice-versa, com uma forma de moção intelectual perpétua, buscamos fazer com que uma seja explicação para a outra. (GEERTZ, 2001, p.105)
}

Assim, crê-se que a categoria de Pórtico mostra-se profícua nesse processo, pois abre possibilidades de olhares tanto para dentro da linha divisória, como um "vazio", quanto para suas relações com outros arranjos globais, das quais esse espaço pode ser criador e/ou criatura. Assim, esse centro, que não é nem brasileiro nem uruguaio, sustenta e é sustentado por uma estrutura que se chama fronteira, fazendo parte de um emaranhado de culturas e legislações locais, estaduais, departamentales, ${ }^{13}$ nacionais, binacionais e internacionais. Circunstância que por si só faz com que a qualificação de "terra sem lei", ou "terra de ninguém", seja completamente desprovida de sentido.

\section{REFERÊNCIAS}

ALBORNOZ, Vera do Prado. Armour: uma aposta no pampa. Santa Maria: Pallotti, 2000.

ALBUQUERQUE, José Lindomar. A dinâmica das fronteiras: os brasiguaios na fronteira entre o Brasil e o Paraguai. São Paulo: Annablume, 2010.

ALMEIDA, Letícia N. Les frontières comme territoires de l'attente: l'expérience des Palestiniens dans le sud du Brésil. Colloque international Sociétés, mobilités, déplacements: les territoires de l'attente d'hier à aujourd'hui.Université de La Rochelle, France. Décembre, 2014.

. El contrabando y la ilegalidad em la frontera Brasil-Uruguay: el caso de Rivera y Sant'Ana do Livramento. In: CARRIÓN, Fernando (Org.). Seguridad, planificación y desarrollo en las regiones transfronterizas. Quito: FLACSO, Sede Ecuador: Centro Internacional de Investigaciones para el Desarrollo (IDRC-CRDI), 2013.

ALVAREZ, Marcos César; SALLA, Fernando; ALMEIDA, Letícia Núñez. Violência e fronteiras: uma análise das políticas públicas nos espaços fronteiriços no Brasil contemporâneo. In: Coloque International Analyserles Politiques Publiques Brésiliennes. Paris, 2011. No prelo.

\footnotetext{
${ }^{13}$ O Uruguai se divide em departamentos. Rivera é o município-capital do Departamento de Rivera.
} 
ASSEF, Marlon. Retratos do exílio: solidariedade e resistência na fronteira. Santa Cruz do Sul: EDUNISC, 2009.

BACHIO, Henrique Machado. Praça Flores da Cunha será inaugurada dia 2. A Plateia: Santana do Livramento. 30 dez. 2014. Disponível em:

$<$ http://www.aplateia.com.br/VisualizarNoticia/6161/praca-flores-da-cunha-sera-inauguradadia-2.aspx>. Acesso em: 15 julho 2015.

BRASIL. Lei N ${ }^{\circ}$ 12.095, de 19 de novembro de 2009. Declara Sant'Anna do Livramento, estado do Rio Grande do Sul, cidade símbolo da integração brasileira com os países membros do MERCOSUL. Disponível em: www.planalto.gov.br/ccivil_03/_ato2007-2010/2009/lei /112095.htm. Acesso em: 20 julho 2012.

CANABARRO, J. N. 2009. Disponível em: <http://ducana.zip.net/arch2009-11-01_2009-1107.html>. Acesso: 22 julho 2015.

CARRIÓN, Fernando; ESPÍN, Johanna. Relaciones fronteizas: encuentros y conflitos. Quito: FLACSO, IDRC, 2011.

CASSANEGO, Paulo; BARDESIO, Geovana; HUEZO, Mario. Accountability em órgão binacionais: estudo na Fronteira da Paz. Cadernos Gestão Pública e Cidadania, São Paulo, v. 18, n. 61, Jul./Dez. 2012. Disponível em:

<http://bibliotecadigital.fgv.br/ojs/index.php/cgpc/article/view/3848/5732>. Acesso em: 22 julho 2015.

CLICRBS, Livramento. Prefeitos reivindicam critérios específicos para área de fronteira no Censo. Santana do Livramento. 21 ago. 2010. Disponível em:

$<$ http://wp.clicrbs.com.br/livramento/2010/08/21/prefeitos-reivindicam-criterios-especificospara-area-de-fronteira-no-censo/>. Acesso em: 25 julho 2015.

DORFMAN, Adriana. O legal e o legítimo no contrabando em Santana do Livramento (BR) e Rivera (UY). In: 25 RBA, 11 a 14 de junho, Goiânia, 2006.

ESPÍN, Johanna. Lo internacional sobre lo local en el tratamiento de la frontera norte. Revista Fronteras, n.1. Flacso Sede Ecuador, Quito, Octubre, 2009.

GEERTZ, Clifford. O saber local. Petrópolis: Vozes, 2001.

GOOGLE MAPS. Santana do Livramento. 2015. Disponível em:

<https://www.google.com.br/maps/place/Santana+do+Livramento,+RS/@-31.0859814,55.3158712,6z/data $=! 4 \mathrm{~m} 2 ! 3 \mathrm{~m} 1$ !1s0x95a9ffb202eac28f:0xe25fcf314b630218>. Acesso em: 15 julho 2015.

MACHADO, Lia. Limites e fronteiras: da alta diplomacia aos circuitos da ilegalidade. Revista Território. Rio de Janeiro, v. 8, p. 9-29, 2000.

MAGNANI, José Guilherme. De perto e de dentro: notas para uma antropologia urbana. Revista Brasileira de Ciências Sociais, v.17, n. 49, jun. 2002.

MAGNOLI, Demétrio. O que é Geopolítica ? São Paulo : Editora Brasiliense, 1986. 
MARTINS, José de Souza. Fronteira: a degradação do outro nos confins do humano. São Paulo: Contexto, 2009.

OLIVEIRA, Roberto Cardoso de; Stephen G. Baines (Orgs.). Nacionalidade e etnicidade em fronteiras. Brasília: Ed. UNB, 2005.

RIBEIRO, L. Interações espaciais na fronteira Brasil-Paraguai: as cidades-gêmeas Foz do Iguaçu e Ciudad del Este. Dissertação de Mestrado. PPGG/UFRJ, Rio de Janeiro: 2001.

RUIZ, Olívia. Una reflexión sobre dos fronteras: los casos de Livramento-Rivera y TijuanaSan Diego. Frontera Norte, v. 10, n. 19, Tijuana, enero-junio 1998.

SILVA, Maurício Pinto da. Ações de cooperação em saúde na fronteira Brasil/Uruguai: um estudo sobre o Comitê Binacional de Integração em Saúde de Santana do Livramento-Rivera. Dissertação de Mestrado. PPGPS, UCPEL, Pelotas, dez. 2009.

SILVA, Tomás. Terráqueo sem Terra. 2011. Disponível em:

<http://terraqueosemterra.blogspot.com.br/2011/03/localizacao-regionalizacao-equestoes.html>. Acesso em: 09 agosto 2015.

SIMMEL, Georg. As grandes cidades e a vida do espírito (1903). Mana, Rio de Janeiro, v. 11, n. 2, oct. 2005.

CALPE, 1939.

. Sociología - estudios sobre las formas de socialización. Buenos Aires: ESPASA-

WEBER, Max. Economia e sociedade. Brasília: Ed. UnB, 2009. v. 2. 